Article

\title{
Cross-Media Alliances to Stop Disinformation: A Real Solution?
}

\author{
Bella Palomo * and Jon Sedano \\ Department of Journalism, University of Malaga, 29018 Malaga, Spain; E-Mails: bellapalomo@uma.es (B.P.), \\ jon@uma.es (J.S.) \\ * Corresponding author
}

Submitted: 3 August 2020 | Accepted: 27 September 2020 | Published: 3 March 2021

\begin{abstract}
Social networks have surpassed their intermediary role and become gatekeepers of online content and traffic. This transformation has favored the spread of information disorders. The situation is especially alarming in Spain, where $57 \%$ of Spaniards have at some moment believed false news. Since 2016, First Draft has promoted several collaborative verification projects that brought together newsrooms to fact-check false, misleading and confusing claims circulating online during presidential elections in several countries. The main objective of this article is to study the collaboration forged between newsrooms in Spain in order to debunk disinformation contents in 2019 under the name of Comprobado (Verified) and the impact of this initiative. Applying a methodological approach based on non-participant observation, interviews, content analysis of reports, scientific articles, books and media archives, we examine the internal uses of this platform, how journalists verified public discourse, the strategies and internal agreements implemented, and the degree of participation of the 16 media involved. Results show that only half of the initiatives begun were transformed into published reports, and the media impact achieved was limited. Finally, we note that the principal reasons for the frustration of the project were its improvised implementation, due to the date of the election being brought forward, and the scant culture of collaboration in the sector. In Spain at least, cross-media alliances are still an exception.
\end{abstract}

\section{Keywords}

alliance; collaboration; collaborative journalism; cross-media; disinformation; fact-checking; newsroom

\section{Issue}

This article is part of the issue "Disinformation and Democracy: Media Strategies and Audience Attitudes" edited by Pere Masip (University Ramon Llull, Spain), Bella Palomo (University of Málaga, Spain) and Guillermo López (University of Valencia, Spain).

(C) 2021 by the authors; licensee Cogitatio (Lisbon, Portugal). This article is licensed under a Creative Commons Attribution 4.0 International License (CC BY).

\section{Introduction}

The proximity between media companies and active audiences has been the focus of numerous professional projects and investigations over the last decade (Engelke, 2019), which have analyzed questions from basic interaction (Domingo et al., 2008) to user involvement as co-creators (Sixto-García, López-García, \& Toural-Bran, 2020) of news under the label of user-generated content (Palomo, Teruel, \& Blanco, 2019), or the tensions derived from that relationship (Lewis, 2012). This practice of integration coexists with another participatory model involving collaboration between competing media, which has ceased to be a utopian aspiration following the success achieved by some of these initiatives. One of the most relevant is the Panama Papers macro-project, which involved teamwork by more than 400 journalists from 107 media organizations in 80 countries, and was recognized with a Pulitzer Prize. This type of partnership is central to ProPublica, and has been applied in stories like Unheard, Documenting Hate or Electionland (Eads, 2018). These cases are not something alien to local journalism, where according to the Center for Cooperative Media they have doubled in two years (Wiltshire, 2019).

These joint efforts with colleagues form part of the regular routines of investigative units, and have made it possible to overcome censorship and strengthen security measures in scenarios such as those found in Latin 
America (Cueva Chacón \& Saldaña, 2020). There are also other relevant benefits accompanying these practices, such as: sharing of costs, information and the time required for analyzing big datasets; increasing the scope of content; tackling complex reporting on a global scale; and renewing the news agenda (Carson \& Farhall, 2018).

In this networked media ecosystem, formulas for collaboration between media companies are very diverse and have been taking place for decades. Media like The Seattle Times and The Seattle Post-Intelligencer carried out a joint operating agreement between 1983 and 2009 that consisted in centralizing advertising, production and circulation, and the publication of a combined Sunday edition that allowed editorial competition to be preserved (Picard, 2015). Following this same line, cross-promotion, the design and the adoption of productive protocols ("Trusted News Initiative (TNI) steps up," 2020) have given rise to proximity between some media companies.

The expansion of the culture of innovation has also transformed some newsrooms into laboratories that are open to experimentation, such as hiring developers and data journalists or creating hybrid work teams that boost creativity in order to compete in changing environments (Gade \& Perry, 2003), which could solve some of the basic problems of legacy media (Klaß, 2020). Media and professional congresses have had recourse to creative spaces like hackathons to construct prototypes, explore new concepts or seek solutions to diverse challenges that fall outside the typical workday in a brief period of time, combining their energies through multidisciplinary teams (Boyles, 2017) of coders, designers and journalists, whose members on occasion had never worked together before (Toporoff, 2016).

This networking proves to be especially necessary for fact-checkers. Conscious of their reduced impact (Masip et al., 2020) and the financing problems involved, fact-checkers have forged alliances amongst themselves to strengthen their activity and, in parallel, have collaborated with media of record to reach wider audiences (Singer, 2020). These synergies have been especially evident during the global infodemic derived from the Covid-19 crisis, when the diffusion of fake news increased notably and citizens promoted this without being aware of it (Destiny \& Omar, 2020). Outstanding in this respect is the union of 91 verification units from 70 countries to feed the database The CoronaVirusFacts/DatosCoronaVirus Alliance, supported by the International Fact-Checking Network. This network also inspired the creation of LatamChequea in Latin America, a collaborative platform funded by Google in which 35 organizations coordinated by Chequeado registered more than 2,000 rumors related to the Coronavirus, content that they offered on open access for its reuse to speed up the work of journalists.

But prior to the arrival of the world health crisis, numerous studies had demonstrated that the information disorder was becoming especially acute in the polit- ical context (Freelon \& Wells, 2020). In the United States many local and national news outlets featured political fact-checking for the 2012 and 2016 elections (Graves, 2016a). Concern about the impact that the circulation of false content on social media might have on elections (Aral \& Eckles, 2019) is also favoring collaboration amongst major news and global tech organizations. An example of this is the emergence of The Trusted News Initiative (TNI), an international network founded in 2019 with the aim of protecting audiences and users from disinformation. The partners working together to identify and stop the spread of dangerous content are AFP, AP, BBC, CBC/Radio Canada, European Broadcasting Union, Financial Times, Reuters, The Wall Street Journal, The Washington Post, The Hindu, Facebook, Google, Microsoft, Twitter, First Draft, and the Reuters Institute for the Study of Journalism. These companies share an early warning system where organizations co-operate, sharing alerts rapidly when they discover disinformation which threatens human life or disrupts democracy during elections, and avoiding the republication of falsehoods. This was put into practice during the UK 2019 General Election, the Taiwan 2020 General Election, and the Coronavirus crisis ("Trusted News Initiative (TNI) steps up," 2020).

That dynamic of activity was implanted by First Draft in earlier projects with a double aim: to defend the media from those accusing them of constructing fake news by increasing the credibility of journalistic production, thus revitalizing the tradition of truth-seeking in the field (Graves, 2016a); and to reduce the social confusion caused by the intense diffusion of false or malicious content. To achieve this end, since 2016 First Draft has promoted collaborative reporting and crosschecking experiences around elections in the United States, France, United Kingdom, Germany, Brazil, Nigeria, Spain, Uruguay, Argentina, Australia and the European Union, based on the understanding that competing newsrooms can work together for more effective, efficient and responsible news coverage. Similarly, this collaboration prevents the duplication of newsrooms debunking the same content and ensures that quality information reaches large audiences. According to Claire Wardle, First Draft Director, "to crosscheck a report means reviewing and approving the verification steps taken by another newsroom, adding the logo of your organization alongside other contributing partners, and then amplifying the report to existing audiences" (Wardle, Pimenta, Conter, Días, \& Burgos, 2019, p. 4). One of the initiatives that generated less media interest and produced a smaller number of reports was the project developed in Spain, as can be seen in Table 1.

This research focuses on the Spanish case because of the particularities concentrated in this scenario. For many years social media have been the preferred starting point for the consumption of daily news in Spain (Gottfried \& Shearer, 2016). They have surpassed their intermediary role and become gatekeepers of 
Table 1. List of First Draft election cross-checking projects

\begin{tabular}{|c|c|c|c|}
\hline Project & Partners & Reports & Year \\
\hline $\begin{array}{l}\text { CrossCheck } \\
\text { France }\end{array}$ & $\begin{array}{l}\text { AFP, BuzzFeed News, France 24, The Observers, La Voix du Nord, Bellingcat, } \\
\text { Rue89 Bordeaux, Les Echos, Rue89 Strasbourg, Libération, France Télévisions, } \\
\text { Les Décodeurs, Storyful, ScienciesPo, Global Voices, Street Press, } \\
\text { Ouest France, La Provence.com, Rue89 Lyon, Facto Scope 2017, L'express, } \\
\text { Nice-Matin, Le Journal du Dimanche, Explicite, Centre France, LCI, Le Monde, } \\
\text { Sud Ouest, Euronews, Meedan, Le Télégramme, L'avenir.net, Euractiv, } \\
\text { Saphir News, London School of Economics, } 4 \text { News, Bloomberg, EPFT, Google } \\
\text { News Lab, Facebook, CFJ, Crowdtangle, Hearken, NewsWhip, SAM, First Draft. }\end{array}$ & 67 & 2017 \\
\hline
\end{tabular}

Comprova Brazilian Association of Investigative Journalists, NSC Comunicação, UOL, O Povo, Metro Brasil, Exame, Nova Escola, Piauí, Veja, Band News, Band TV, Canal Futura, SBT, Band News FM, Bandeirantes, AFP, Nexo Jornal, Poder360, Gazeta Online, GaúchaZH, Gazeta do Povo9, Projor, Google News Initiative, Facebook Journalism Project, National Newspaper Association (ANJ), David Rockefeller Center for Latin American Studies at Harvard University, Aos Fatos Brazilian fact-checking agency, Armando Alvares Penteado Foundation (FAAP), RBMDF Advogados Brazilian law firm, CrowdTangle, NewsWhip, Torabit, Twitter, WhatsApp, First Draft.

Comprobado AFP, Ara, Datadista, Diario de Navarra, EFE, El Confidencial, eldiario.es, Spain El Faradio, Europa Press, La Marea, Newtral, Politibot, Público, RTVE, Servimedia, Maldita.es, First Draft.

CrossCheck Premium Times, Daily Trust, News Agency of Nigeria, AFP, The Nation, Nigeria Tribune, Africa Check, The Guardian, Punch, The Sun, Channels Television, The Cable, The Niche, Sahara Reporters, Freedom Radio, University of Lagos Mass Communication Department, CODE, International Centre for Investigative Reporting, Google News Initiative, Open Society Foundations, MacArthur Foundation, Ford Foundation, WhatsApp, Facebook Journalism Project, First Draft.

CrossCheck Australia

Reverso Argentina
The Centre for Media Transition at the University of Technology Sydney, Crikey, SBS News, NZME, UTS, RMIT University, AUT, HKU, QUT, First Draft.

0223, 12noticias TV, 7Corrientes, A24, ADN Sur, AM750, Ámbito, Anfibia, BAE Negocios, BBC Mundo, Bumerang News, C5N, Cable a Tierra, Canal 10 Mar del Plata, Canal 10 Tucumán, Canal 13, Canal4 (Posadas), Canal 7, Clarín, Crónica, Cuarto Poder Diario, Diario Andino, Diario Huarpe, Diario Jornada, Diario La Mañana (Formosa), Diario Popular, Diario UNO, Diarios Bonaerenses, Economis, El Cronista, El Día, El Diario de Miramar, El Liberal, El Litoral, El Nueve, El Territorio, El Tribuno, Filo.News, FM 89.3 Santa María de las Misiones, FM Cielo 103.5, FM El aire de integración, FM La Redonda, FM Milenium 106.7, Hoy Día Córdoba, Infobae, Infocielo, Infopico, Iprofesional, La Capital, La Capital de Mar del Plata, La Gaceta, La Izquierda Diario, La Nación, La Nota, La Nueva, La Voz del Interior, LatFem, Los Andes, LT7 Radio Provincia de Corrientes AM 900, LT17 Radio Provincia Misiones, LU2, Marcha, MDZ online, MDZ Radio, Mega 98.3, Mendoza Post, Meridiano55.com, Milénico, Minutouno.com, Misiones Online, Misiones Opina, Nodal, Noticias Jesús María, Noticias Mercedinas, OPI, Página 12, Pausa, Periódicas, POP Radio, Portal Misiones, Presentes, Primera Edición, QUÉ Digital, Radio Andina 90.1, Radio con Vos, Radio Mitre, Radio Nihuil, Radio10, RedAcción, Revista Hamartia, Río Negro, Rosario3, Sitio Andino, SL24, Taringa, Telefe, Telégrafo, Tiempo de San Juan, Tiempo del Este, TKM, TN, TVA, TV Pública, Unidiversidad, UNO, vaga fiebre, Verte, Vía País, Chequeado, AFP Factual, First Draft, Pop-up Newsroom. 
Table 1. (Cont.) List of First Draft election cross-checking projects

\begin{tabular}{llcc}
\hline Project & Partners & Reports & Year \\
\hline Verificado & La Diaria, Búsqueda, El País, Brecha, En Perspectiva, Cori, AFP, Océano FM, & 76 & 2019 \\
Uruguay & Radio Carve, Radio Monte Carlo, Radio Sarandí, Radio Universal, & \\
& RadioMundo, Radio41, Crónicas, TV Ciudad, Efe, Sudestada, UY Press, Martes, \\
& Maldonado Noticias, Organización de Prensa del Uruguay, Asociación de & \\
& Periodistas del Uruguay, Nadie Chequea Nada, UYCheck.com, Universidad de \\
& la República, Universidad de Montevideo, Universidad Católica del Uruguay, \\
& Universidad ORT, Facebook, Google News Initiative, Fundación Avina, \\
& First Draft. \\
\hline
\end{tabular}

online content and traffic. Parallel to this, according to the Reuters Report 2020 (Newman, Fletcher, Schultz, Andi, \& Nielsen, 2020), the country ranks first in terms of news consumption via mobile devices (73\%) and tenth via WhatsApp (34\%), which is where the greatest number of hoaxes are propagated (Salaverría et al., 2020). These transformations have favored the spread of information disorders. The forecasts show that in 2022 citizens of developed countries will consume more disinformation than true news, because false content is $70 \%$ more likely to viralize and be retweeted compared to truthful information (Vosoughi, Roy, \& Aral, 2018). The situation is especially alarming in Spain where $57 \%$ of Spaniards have at some moment believed false news. The Eurobarometer Fake News and Online Disinformation (Directorate-General for Communications Networks, Content and Technology, 2018) also identifies the Spaniards as the European citizens who have the most difficulties in detecting this type of content and as being amongst those most concerned about this issue in the world (Nicholls, Fletcher, Kalogeropoulos, \& Nielsen, 2019).

These antecedents explain why in the spring of 2019 a coalition called Comprobado (Verified) was formed in Spain. This was coordinated by First Draft and Maldita and was initially made up of 16 media with the goal of putting a brake on disinformation during an intense electoral period, since in April and May Spanish citizens were participating in national, municipal and European elections.

The novelty of this article lies in setting out the internal work dynamic developed in this platform and analyzing the media visibility the project achieved.

\section{Literature Review}

The professional and academic debate on false content has intensified since 2016. During an initial conceptual phase the definition of fake news was clarified (Tandoc, Lim, \& Ling, 2018) and use of the term was even discouraged (Wardle, 2017); the three types of information disorder were defined (misinformation, disinformation and malinformation); and it was established that satire and parody, false connection, misleading content, false context, imposter content, manipulated content and fabricated content constitute the seven categories of information disorder (Wardle, 2018). Due to the electoral context that determined this investigation, our article prioritizes the concept of disinformation because it "refers to situations where actors driven by political and/or economic interests, produce and distribute information intended to disinform for their own ends" (Westlund \& Hermida, in press).

More recently, numerous investigations have focused on the process and impact of verification, reflecting the exponential growth of this activity. According to Duke Reporters Lab, in 2014 there were 44 registered fact-checkers, while in 2020 the figure has risen to 290 (Stencel \& Luther, 2020). Although by continent the greatest number of projects is concentrated in Europe (85), it is worth stressing the efforts made in Africa, Asia and South America, where the offer has doubled. The complexity of disinformation has also required the involvement of European institutions, governments and technological companies to contribute to its reduction. France and Germany were pioneers in passing laws to identify, stop and penalize those intending to propagate fake news (López-García, Vizoso, \& Pérez-Seijo, 2019), while Facebook has allied itself with third-party factcheckers in order to help improve quality (Saurwein \& Spencer-Smith, 2020).

The peculiarities of this international multilocalization have been analyzed by Palau-Sampio (2018), who shows that no homogeneity exists in the model for evaluating the content that is subject to verification by the fact-checkers, and she suggests resolving this lack of uniformity by establishing a universal procedure.

Investigations focusing on the collaboration/factchecking relationship prove to be scarce, and tend to provide a positive perspective on its implementation. Thus, earlier studies have analyzed cross-checking experiences as a legitimization strategy of the journalism field in response to disinformation, and have discovered how the description of the verification process has developed into new and successful narratives and formats (Young, Jamieson, Poulsen, \& Goldring, 2018), where false content is also transformed into news (Trevisan Fossá \& Müller, 2019). The transparency of such procedures is a basic requisite for transmitting journalistic truth (Humprecht, 2020; Kovach \& Rosenstiel, 2007). 
Nonetheless, this emergent practice has not been free of criticism. Fact-checkers have been accused of being partisan (Stencel, 2015), and it has even been suggested that fact-checking in general is unsuccessful in reducing misperceptions. Brandtzæg and Følstad (2017) analyzed users' perceptions of three fact-checking services and concluded that users with negative perceptions were trapped in a perpetual state of informational disbelief. Moreover, considered from the professional perspective, journalists regard fact-checking services with caution and skepticism, as they need to have a high degree of control over the process, which can prove difficult with third-party services (Brandtzæg, Følstad, \& Chaparro, 2018).

Graves and Cherubini (2016) distinguish two models of fact-checkers: the newsroom model; and the NGO model. First Draft has opted for a hybrid model that integrates media companies and independent fact-checkers or professional associations and is free of editorial and business constrains in order to obtain a wide reach and ensure that nonpartisan information is diffused. To gain a better understanding of how this experience was managed in the Spanish scenario, the following research questions were posed:

RQ1: What was the internal work dynamic in Comprobado and how did the journalists adopt these routines?

RQ2: What repercussion did this media collaboration have?

\section{Methods}

This article presents an explorative approach to a case study, the Spanish project Comprobado, through the application of mixed methods. The integration of qualitative and quantitative data helped in obtaining a more complete analysis, which is also necessary due to the novelty of the object of study. Antecedents in the analysis of the fact-checking movement in journalism also had recourse to ethnography in order to demonstrate that mechanical testing to verify facts is a complex matter, and that fact-checkers base themselves on multiple pieces of evidence, not always conclusive, until they achieve factual coherence or a triangulation of the truth (Graves, 2016b). The present investigation enquires more deeply into this type of routine. In our case data are derived from more than 50 hours of observing procedures, training sessions and interviews, reports and a systematic analysis of the activity developed in CrossCheck, the work platform used by the media coalition. The benefits derived from the complementarity of online observations, interviews and content analysis for data-gathering in Internet-based research have been defended previously (Sade-Beck, 2004).

The University of Malaga was given the opportunity to partner with this experimental project, applying non-participant observation during its realization and participating in all the meetings as it formed part of the deliberative council, including the final one where the post-mortem review occurred (Collier, DeMarco, \& Fearey, 1996). Over the course of three months, the period for which the project was active, data referring to the production routines was collected, a methodology that has also been applied in studies concerned with the same question (Henderson, 2020). From the first meeting in February 2019 until the final one in May, a diary was kept containing field notes that registered the perceptions of the fact-checkers concerning the project and how they discuss their methods and proposed solutions. For ethical reasons the identities of the participating journalists have been withheld.

The main advantage of obtaining ethnographic information from the virtual social sphere is that it provides accessibility to subjects who are physically remote from the researcher. That is why, in the second place, all of the 82 investigations housed on the CrossCheck platform and the 250 comments by 29 jounalists derived from them between 10 April and 25 May 2019, were subjected to a content analysis. This analysis was carried out using a datasheet designed to identify: 1 ) investigations started; 2) investigations published; 3) labels applied, 4) journalist and medium that started the investigation; 5) journalists and media participating in the verification; 6) internal comments and debates generated; 7) theme and political parties mentioned; 8) origin of content; 9) verification strategies; 10) evidence used; 11) media that validate the investigation. This analysis occurred over the lifetime of the project, making it possible to produce results that invited reflection during the project meetings.

In the third place, to determine the reach of both the project and the verifications in the collaborating media, an analysis was made of the word 'comprobado' in the press archives of the media, which was complemented by a Boolean search in Google (example: 'comprobado' site:afp.com) and the published tweets. Obtaining these quantitative data made a parallel approach with other crosscheck initiatives possible. The period of analysis was established from 1 March to 30 June in order to detect prior and post-project news coverage.

Once the project had concluded, the qualitative research was completed with in-depth interviews as a data collection method (Alshenqeeti, 2014) in order to try to understand the initative from the subject's point of view. Semi-structured interviews were conducted by phone with four journalists to learn their evaluation of the experience, highlighting the strengths and weakness of cross-checking in Spain. The profiles of these interviewees were as follows: one of the project coordinators; one of the journalists who had been most active during the project; and two legacy media journalists who attended the first meetings but whose media finally refused to participate. None of the journalists who had been less active on the project agreed to be interviewed. All the interviews together with the notes and comments 
were uploaded to the Atlas.ti application to categorize the content and enrich the qualitative results.

\section{Results}

\subsection{Internal Involvement to Build Trust}

In 2018 Maldita and First Draft developed a collaborative fact-checking project in Spain, which replicated the successes achieved in France and Brazil. According to the observations, the rescheduling of the elections upset the planned chronogram and made it necessary to design the initiative rapidly. In February 2019 representatives of 40 Spanish newsrooms were brought together in Madrid to convince them that uniting experiences would favor truth production, and that collective vigilance would make it easier for journalism to perform its function as a counter-power. Concerns about professional value and status were the main motivations for journalists to practice fact-checking (Graves, Nyhan, \& Reifler, 2016). During the conference the project was set out, the social and journalistic benefits of this working formula were addressed and several experts held verification workshops. The meeting was held in an atmosphere of 'friendly competitors,' but there was also prudence and skepticism.

The initial requisite established by First Draft to be able to launch the project was securing the participation of more than ten media that would represent the national, regional and local spheres. Having obtained the initial collaboration of 16 media (Table 2), it was consensually decided to work under the name of Comprobado. This decision was influenced by their Brazilian predecessor, Comprova, and by an integrative intention, since the name CrossCheck Spain might discourage participation by pro-independentist media. This macro-project was a pioneer in Spain and commenced its activities on 10 April with a pre-test, while its final verification took place on 25 May. At that moment the CrossCheck platform had a register of 55 users distributed across the following organizations: First Draft/CrossCheck (10), Maldita (8), Ara (5), RTVE (5), Newtral (4), Efe (4), Eldiario.es (3), AFP (2), Datadista (2), El Confidencial (2), El Faradio (2), La Marea (2), Público (2), Diario de Navarra (1), Europa Press (1), Politibot (1), and University of Malaga (1).

None of the national newspapers of record joined the project. The interviews we conducted showed that this was a foreseeable handicap. As one of the reporters attending the initial meeting observed, "We journalists were better prepared than the media themselves. The people in charge of the latter were distrustful of sharing part of their work with competitors." The journalists shared various hypotheses for this investigation. While some alluded to the arrogance of the mainstream media that believe they don't need help in fulfilling their daily work or to the impossibility of their making an editor available in the middle of an electoral campaign, others indicated that the real motive was the effort and difficulties involved in setting an initiative underway that did not form part of their normal routine. But what emerged as the common nexus of all these suppositions was the lack of a collaborative culture. One of the founders of Maldita noted that "a considerable amount of social engineering [was done] to convince them, but more time was needed to achieve it."

The prior training of participants was not analyzed, and this could be the key to the success of crosschecking projects. We were informed by Maldita that a fact-checker requires some 25-30 hours training, and that daily practice for months and internal debates are needed for resolving a verification as best as possible. In this project, following an initial pre-test proposed by a member of First Draft, the journalists began their activity on the CrossCheck platform. Each reporter could create

Table 2. Typology of the media participating in Comprobado.

\begin{tabular}{llc}
\hline Media & Typology & Founded \\
\hline AFP & International news agency & 1835 \\
Ara.cat & Catalan newspaper with pro-independence ideology & 2010 \\
Datadista & Online native medium focused on data journalism & 2016 \\
Diario de Navarra & Conservative newspaper & 1903 \\
EFE & National news agency & 1939 \\
El Confidencial & Online native newspaper with liberal ideology & 2001 \\
Eldiario.es & Online native newspaper with left-wing ideology & 2012 \\
El Faradio & Online native newspaper focused on local journalism & 2012 \\
Europa Press & National news agency & 1953 \\
La Marea & Magazine and online newspaper with republican ideology and co-operative model & 2012 \\
Maldita & Fact checker & 2018 \\
Newtral & Fact checker & 2018 \\
Politibot & Telegram bot focused on political content & 2016 \\
Público & Online newspaper with left-wing ideology & 2007 \\
RTVE & National public broadcasting service & 2007 \\
Servimedia & National news agency & 1988 \\
\hline
\end{tabular}


an investigation, publishing a post, inserting images and identifying tags, and sending the alert to the rest of the coalition representatives to evaluate the verification. When at least three media confirmed the same result they contributed their logo and each collaborating medium could publish the report-card-designed to facilitate its distribution and consumption in mobile formatand the procedure applied to reach the conclusion of whether the content was true or false.

Of the 16 participating media, 9 were digital native media. Preliminary findings suggest that digital native media were the most active when it comes to collaboration, which coincides with other prior studies that also concluded that the big challenge lay in persuading the legacy media (Hatcher \& Thayer, 2016; Méndez, Palomo, \& Rivera, 2020). Also noteworthy was the participation of three news agencies, which was justified by their traditional commitment to verifying content (Wishart, 2018). The project coincided with the birth of specialized units, such as Verifica RTVE and Efe Verifica.

Collaboration was open to all the news companies that respected the code of principles (accuracy, ethical responsibility, fairness and impartiality, independence, transparency) and whose request to join was approved by the deliberative council of Comprobado. During the period of the project's realization only one request was received, that of EMA-RTV (Asociación de Emisoras Municipales y Comunitarias de Andalucía de Radio y Televisión).

For six weeks they monitored content that was basically circulating on social media. The source that gave rise to most disinformation was Twitter, which accounted for half of the verifications. 20 percent of the investigations originated in public statements published in the mass media. The results proceeding from WhatsApp, Facebook or Instagram were not very representative since the project lacked accounts that would have favoured interaction on those channels, and the necessary infrastructure for automating the process.

Every time that a member detected possible disinformation, they indicated this on the platform and each medium received an alert, usually with a question as its title, inviting it to participate in the investigation. In more complex cases it was necessary to undertake and explain eight actions to conclude the report. This was due to the need to make searches for several statements and denials on social media, use translators, or even make a request to the Traffic Department for a record of incidents involving the number plate of a vehicle attributed to a political party.

The participating media not only verified content; the essential element in the collaboration consisted in filling out a report-card on which they explained clearly and objectively the steps taken during the verification process, as this narrative consistency strengthened the credibility of the activity and enabled any interested citizen to reproduce the verification. With respect to evidence, the platform made it possible to attach files, photos or links, the latter being the most employed. In spite of the fact that diagnostic tools for verifying content have become increasingly sophisticated, what predominated in the routines was monitoring online conversations in real-time and contacting official sources. During an initial phase they looked for evidence by locating already existing resources (recordings of interviews, electoral programs of parties, reverse image searches, official reports) and if these proved insufficient, they contacted the primary sources. The investigations were centered on about 50 different individuals, and this variety made it necessary to contact some thirty official sources.

In that month and a half, 82 investigations were started and at the end of the project 46 of them met the requirement of having a report-card and being verified by at least three media. The content analysis carried out showed that of the 55 journalists registered on the platform, only 29 collaborated in a verification process during the six weeks that the project was active, and five of the media in the alliance did not validate any investigation. The verification process involving the greatest number of media received support from eight. The most regular contribution proceeded from the team at the public broadcaster RTVE and the fact-checking platform Maldita, which also made the most proposals as they initiated $75 \%$ of the investigations. In this sense, Maldita's initiative was essential to maintaining the project active to the end. This unequal level of participation explains why the main tension and frustration detected in this alliance arose when comparisons were made of the time invested by the media in verifications, a situation that replicated what had happened in previous experiences (Singer, 2004). For one of the most active journalists, the lack of coordination and the unequal participation were the main weaknesses of Comprobado: "We didn't have the sensation that there was real collaboration. What's more, at some moments we had the sensation that there was some competition between the teams."

The circulation of conspiracy theories, malicious readings of political statements and electoral programs, or accusations of electoral fraud and its influence on destabilizing the democratic system, especially during the week leading up to the elections, did not alter the inscrutable attitude of the majority of the media.

Concerning the prominence of political parties in these investigations, an imbalance could also be observed in favor of the more extreme parties. Thus, Unidas Podemos was present in three out of every ten investigations, and Vox, an extreme right-wing party, in two out of every ten. The journalists consulted denied any tendentiousness in the selection, and explained that the choice was determined by the most viral and journalistically relevant content.

The 46 final reports prepared for the Comprobado website reflected four principal categories: unreliable (80.4\%), inconclusive (8.7\%), be aware $(6.5 \%)$, and trustworthy $(4.4 \%)$. Each category appeared in the design of the report-card, influencing its color so that its visual 
appearance would facilitate comprehension and thus avoid resending any unevaluated false content. As many as 14 different subcategories were used to determine the type of unreliable content, with a predominance of content that had been digitally altered, manipulated or proceeded from deliberate fabrication (32.4\%), followed by those for which there was no supporting evidence (18.9\%) and wrong context (16.2\%).

During the project three coordination meetings were held between March and May, at which agreement was reached on patterns and recommendations for action, such as the need for each collaborating medium to allow one editor to dedicate between 5 and 10 hours per week to Comprobado. On 6 May, following the general election of 28 April, another videoconference was held at which a commitment was made to continue the collective fact-checking project during the regional elections, and it was agreed to adopt routines such as the obligation to enter the platform on a daily basis for at least five minutes to crosscheck. It was understood that although not all the teams had the possibility of investigating, they could at least check the verifications of colleagues. On that occasion it was also agreed to create the Telegram group to speed up communications between the 11 journalists who volunteered to participate in that space. The themes of the messages were related to technical problems and alerts to solve errors, although in general communication on this channel was not very fluid, with only 19 messages registered in three weeks. This figure contrasts with the Brazilian case, where approximately 50 journalists who participated in Comprova shared 18,154 messages in their private WhatsApp Group (Wardle et al., 2019, p. 7).

\subsection{The Visibility of Comprobado}

On 11th April the first announcement was made of the birth of this pioneering media alliance in Spain. Maldita and AFP gave the widest diffusion to the initiative, and the practice of a self-reference strategy was also detected when the project started, which enabled it to exceed 5,000 followers on the official Twitter account @ComprobadoES on the first day. Nonetheless, the content analysis confirms that no textual mention of Comprobado at all could be found in five of the sixteen media involved. An analysis of the press archives of the media involved and their social media accounts showed very little self-promotion was carried out during the development of the project, only about 50 news items were localized and the majority concerned the launching of the initiative. This silence was also practiced with the verifications, although the media were under no obligation to publish them. Of the 46 report-cards created, 38 appeared on the official Twitter account @ComprobadoES. This account achieved 124 tweets, although one-third were self-promotions, one-third were new investigations and the remaining third were retweets of verifications. A strong contrast can therefore be noted with respect to the production and impact obtained in other cross-checking projects, although the period of existence of these accounts also differs (Table 3). While @ComprobadoES was active for only two months, @Comprova was still active at the moment when this investigaiton was closed.

The experience in Brazil was one of the most significant since, according to the Comprova Report, $40.4 \%$ of those surveyed said this initiative helped them to decide their vote. In this case, the 146 verifications developed on the Comprova platform were transformed into 1,750 items of content distributed in television news programs, newspapers, magazines and online media (Rinehart, 2019). In Argentina, Reverso exceeded 20,000 followers on Twitter, where 1,447 tweets were published, although that figure was doubled in Mexico, where the highest number of followers was obtained. In Spain, the scant support received from the legacy media lowered expectations and the visibility of the initiative, but other questions also influenced this result, such as the early elections, which made it necessary to precipitate the birth of Comprobado and made it impossible to reproduce the recommended periods. In the case of Comprova, five meetings were held prior to its start-up, including workshops and a bootcamp; grants were offered for participating newsrooms; the project had an open-access website; Facebook and Twitter published adverts supporting its activity and ad campaign groups were created with the result that social media were responsible for almost half of all Comprova's web traffic. Audience proximity was essential for spreading knowledge about Comprova and its usefulness. Proof of this proximity is that there were 350,567 interactions between users and journalists on WhatsApp during the 12 weeks of the

Table 3. Cross-checking projects on Twitter.

\begin{tabular}{lrrrr}
\hline Project & Tuits & Followers & Founded in & Last tweet \\
\hline @VerificadoMX & 3208 & $177,9 \mathrm{k}$ & 02.2018 & 10.07 .2018 \\
@Comprova & 1956 & $28,2 \mathrm{k}$ & 06.2018 & Active \\
@ReversoAR & 1447 & $20,1 \mathrm{k}$ & 05.2018 & 11.12 .2019 \\
@verificadouy & 556 & $16,6 \mathrm{k}$ & 06.2019 & 04.12 .2019 \\
@crosscheckNG & 410 & $02,1 \mathrm{k}$ & 11.2018 & 12.09 .2019 \\
@CrossCheckFR & 186 & $04,6 \mathrm{k}$ & 01.2017 & 01.03 .2019 \\
@ComprobadoES & 124 & $10,2 \mathrm{k}$ & 04.2019 & 11.06 .2019 \\
\hline
\end{tabular}


project, with one-third of the messages proceeding from the audience, which included suspicious claims, images, video or audio messages for the professional team to debunk (Wardle et al., 2019, p. 7). The strategies followed in France (Smyrnaios, Chauvet, \& Marty, 2017) and Argentina were similar.

Although Comprobado's quantitative data were unsuccessful and demonstrate that the model of horizontal coordination to facilitate reaching consensus did not work, at Maldita they consider that the qualitative reading was positive. This was because the experience made it possible to bring together very different newsrooms, share routines between journalists that did not know each other before, and spread knowledge about fact-checking and its implementation with new formulas via outsourcing (Méndez et al., 2020). The system's open character was also one of the project's main weaknesses according to Maldita, and one of the lessons learned. If a similar initiative is attempted in the future, it will only involve the more committed companies.

\section{Conclusions}

The media industry is adapting to a post-truth age, developing innovative approaches in order to produce quality journalism and repair its damaged credibility (Carson \& Farhall, 2018). Both competition and collaboration are considered relevant actions for surviving in the temporalities of the media ecology (Dodds, 2019; Eads, 2018). The actions implemented in this respect in newsrooms must also consider the expectations of audiences, who are demanding objective reporting, analysis, explanation and transparency from the journalist (Loosen, Reimer, \& Hölig, 2020). The initiatives promoted by First Draft have taken all these characteristics into account, designing places of truth production (Trevisan Fossá \& Müller, 2019), a new model where the watchdog role is shared and the function of a gatekeeper working for the public interest is strengthened. This is an old-new journalism that is more open and responsible.

This article has analyzed the internal activity of the media that formed an alliance to put a brake on the circulation of false news stories during the 2019 elections in Spain and the visibility received by that initiative. In answer to the first question posed, this investigation describes a systematic strategy whose implementation depended on the willingness of each journalist. In theory, the combination of effort frees more time for developing other stories in depth, and audiences profit from these strategies. However, not all the media believed that working together rather than separately would be more valuable and efficient; only a dozen journalists from five media were active and carried out a forensic content analysis, with half of the initiatives left unfinished. There was a shortage of time for convincing, trust and commitment.

That is why in spite of the success achieved in previous cross-checking initiatives (Wardle et al., 2019), this collaboration in Spain had less impact. The project revealed the existence of a collision of cultures (Dailey, Demo, \& Spillman, 2005) that provoked the resistance of the big national news outlets to participating in this coalition and an uneven involvement by the collaborating journalists. While it is possible to identify practices related to the convergence continuum model, and especially the coopetition stage (Dailey et al., 2005), the abovementioned factors reduced the initiative's impact. This was also influenced by the fact it did not reproduce the same model that was implanted in countries like Brazil and Argentina, where coordination and contacts were designed and established during the six months prior to the elections, while in the Spanish case Comprobado's development was precipitated. Similarly, accessibility to Comprobado's activity was articulated around two axes: the diffusion that each medium decided to give to a verification, and a Twitter account.

With respect to the study's limitations, an analysis of the Spanish case cannot be generalized to the rest of the CrossCheck initiatives, and the data from the Brazilian case shows that there can be clear differences between countries. As Humprecht (2020) observes, professional fact-checking depends on the country in which one lives and on occasions fact-checking plays a less important role in non-Anglophone countries. This preliminary exploration of a political and media context as polarized as the Spanish case makes it possible to propose a comparative study with the rest of the countries, and even a longitudinal analysis if the initiative is repeated in future elections. Additionally, we suggest pursuing the qualitative approaches that make it possible to determine how journalists and audiences perceive the work developed by cross-checking experiences, discover the editorial motivations invoked by media so as not to participate in such alliances, and whether a program of incentives would alter this reluctance or even favor the long-term sustainability of such collaborations.

\section{Acknowledgments}

This work was supported by the project "The Impact of Disinformation on Journalism: Contents, Professional Routines and Audiences" (PID2019-108956RB-I00).

\section{Conflict of Interests}

The authors declare no conflict of interests.

\section{References}

Alshenqeeti, H. (2014). Interviewing as a data collection method: A critical review. English Linguistic Research, 3(1), 39-45.

Aral, S., \& Eckles, D. (2019). Protecting elections from social media manipulation. Science, 365(6456), 858-861. 
Boyles, J. L. (2017). Laboratories for news? Experimenting with journalism hackatons. Journalism, 21(9), 1338-1354. https://doi.org/10.1177/14648849177 37213

Brandtzæg, P. B., \& Følstad, A. (2017). Trust and distrust in online fact-checking services. Communications of the ACM, 60(9). https://doi.org/10.1145/3122803

Brandtzæg, P. B., Følstad, A., \& Chaparro, M. A. (2018). How journalists and social media users perceive online fact-checking and verification services. Journalism Practice, 12(9), 1109-1129.

Carson, A., \& Farhall, K. (2018). Understanding collaborative investigative journalism in a "post-truth" age. Journalism Studies, 19(13), 1899-1911.

Collier, B., DeMarco, T., \& Fearey, P. (1996). A defined process for Project post mortem review. IEEE Software, 13(4), 65-72.

Cueva Chacón, L., \& Saldaña, M. (2020). Stronger and safer together: Motivations for and challenges of (trans)national collaboration in investigative reporting in Latin America. Digital Journalism. Advance online publication. https://doi.org/10.1080/ 21670811.2020.1775103

Dailey, L., Demo, L., \& Spillman, M. (2005). The convergence continuum: A model for studying collaboration between media newsrooms. Atlantic Journal of Communication, 13(3), 150-168.

Destiny, O., \& Omar, B. (2020). Fake news and Covid-19: Modelling the predictors of fake news sharing among social media users. Telematics and Informatics, 56, 101475. https://doi.org/10.1016/j.tele.2020.101475

Directorate-General for Communications Networks, Content and Technology. (2018). Flash Eurobarometer 464: Fake news and disinformation online. Brussels: European Commission. Retrieved from https:// op.europa.eu/en/publication-detail/-/publication/ 2d79b85a-4cea-11e8-be1d-01aa75ed71a1/ language-en

Dodds, T. (2019). Reporting with WhatsApp: Mobile chat applications' impact on journalistic practices. Digital Journalism, 7(6), 725-745.

Domingo, D., Quandt, T., Heinonen, A., Paulussen, S., Singer, J. B., \& Vujnovic, M. (2008). Participatory journalism practices in the media and beyond. Journalism Practice, 2(3), 326-342.

Eads, D. (2018, June 19). When do reporters collaborate, and when do they compete? ProPublica. Retrieved from https://www.propublica.org/article/askpropublica-illinois-reporters-journalismcollaboration-between-newsrooms

Engelke, K. (2019). Online participatory journalism: A systematic literature review. Media and Communication, 7(4), 31-44.

Freelon, D., \& Wells, C. (2020). Disinformation as political communication. Political Communication, 37(2), 145-156.

Gade, P. J., \& Perry, E. L. (2003). Changing the newsroom culture: A four-year case study of organiza- tional development at the St. Louis Post-Dispatch. Journalism \& Mass Communication Quarterley, 80(2), 327-347.

Gottfried, J., \& Shearer, E. (2016, May 26). News use across social media platforms 2016. Pew Research Center. Retrieved from https://www.journalism.org/ 2016/05/26/news-use-across-social-mediaplatforms-2016

Graves, L. (2016a). Deciding what's true: The rise of political fact-checking in American journalism. New York, NY: Columbia University Press.

Graves, L. (2016b). Anatomy of a fact check: Objective practice and the contested epistemology of fact ckecking. Communication, Culture \& Critique, 10(3), 518-537.

Graves, L., \& Cherubini, F. (2016). The rise of factchecking sites in Europe. Oxford: Reuters Institute for the Study of Journalism.

Graves, L., Nyhan, B., \& Reifler, J. (2016). Understanding innovations in journalism practice: A field experiment examining motivations for fact-checking. Journal of Communication, 66(1), 102-138.

Hatcher, J. A., \& Thayer, D. (2016). Assessing collaboration in one media ecosystem. Journalism Practice, 11(10), 1283-1301.

Henderson, K. (2020). Marketing the construction of reality: Multiplatform production routines and the renegotiation of journalistic role identities in a legacy local televisión newsroom. Journalism. Advance online publication. https://doi.org/10.1177/1464 884920940940

Humprecht, E. (2020). How do they debunk "fake news"? A cross-national comparison of transparency in fact checks. Digital Journalism, 8(3), 310-327.

Klaß, N. (2020). Open innovation in media innovation research: A systematic literature review. Journal of Media Business Studies, 17(2), 190-218.

Kovach, B., \& Rosenstiel, T. (2007). The elements of journalism: What newspeople should know and the public should expect. New York, NY: Three Rivers Press.

Lewis, S. C. (2012). The tension between professional control and open participation. Information, Communication \& Society, 5(6), 836-866.

Loosen, W., Reimer, J., \& Hölig, S. (2020). What journalists want and what they ought to do (in)conguences between journalists' role conceptions and audiences.' Journalism Studies, 21(12), 1744-1774. https://doi.org/10.1080/1461670X.2020.1790026

López-García, X., Vizoso, A., \& Pérez-Seijo, S. (2019). Verification initiatives in the scenario of misinformation: Actants for integrated plans with multi-level strategies. Brazilian Journalism Research, 15(3). https:// doi.org/10.25200/BJR.v15n3.2019.1215

Masip, P., Almenar, E., Aran, S., Capilla, P., Puertas, D., Ruiz, C., . . . Zilles, K. (2020). El consumo de información durante el confinamiento por el coronavirus: Medios, desinformación y memes [Information consumption during coronavirus confinement: 
Media, misinformation and memes]. Barcelona: Ramon Llull University. Retrieved from https://www. researchgate.net/publication/340685890_El_ consumo_de_informacion_durante_el_ confinamiento_por_el_coronavirus_medios_ desinformacion_y_memes

Méndez, A., Palomo, B., \& Rivera, A. (2020). Managing social networks in online-native newsrooms: When less means more. Media and Communication, 8(2), 124-134.

Newman, N., Fletcher, R., Schultz, A., Andi, S., \& Nielsen, K. (Eds.). (2020). Digital news report 2020. Oxford: Reuters Institute for the Study of Journalism.

Nicholls, N., Fletcher, R., Kalogeropoulos, A., \& Nielsen, K. (Eds.). (2019). Digital news report 2019. Oxford: Reuters Institute for the Study of Journalism.

Palau-Sampio, D. (2018). Fact-checking and scrutinity of power: Supervision of public discourses in new media platforms from Latin America. Communication \& Society, 31(3), 347-365.

Palomo, B., Teruel, L., \& Blanco, E. (2019). Data journalism projects based on user-generated content. How La Nacion Data transforms active audience into staff. Digital Journalism, 7(9), 1270-1288.

Picard, R. G. (2015). Natural death, eutanasia, and suicide: The demise of joint operating agreements. Journal of Media Business, 4(2), 41-64.

Rinehart, A. (2019, June 26). What we learned in Brazil about building trust and collaborations. First Draft. Retrieved from https://firstdraftnews.org/latest/ what-we-learned-in-brazil-about-building-trustand-collaborations

Sade-Beck, L. (2004). Internet ethnography: Online and offline. International Journal of Qualitative Methods, 3(2), 45-51.

Salaverría, R., Buslón, N., López-Pan, F., León, B., LópezGoñi, I., \& Erviti, M. C. (2020). Desinformación en tiempos de pandemia: Tipología de los bulos sobre la Covid-19 [Disinformation in times of pandemic: Typology of hoaxes on Covid-19]. El Profesional de la Información, 29(3). https://doi.org/10.3145/epi. 2020.may.15

Saurwein, F., \& Spencer-Smith, C. (2020). Combating disinformation on socialo media: Multilevel governance and distributed accountability in Europe. Digital Journalism, 8(6), 820-841.

Singer, J. (2004). Strange bedfellows? The diffusion of convergence in four news organizations. Journalism Studies, 5(1), 3-18.

Singer, J. (2020). Border patrol: The rise and role of factcheckers and their challenge to journalists' normative. Journalism. Advance online publication. https:// doi.org/10.1177/1464884920933137

Sixto-García, J., López-García, X., \& Toural-Bran, C. (2020). Oportunidades para la cocreación de contenidos en los diarios nativos digotales [Opportunities for content co-creation in digital native newspapers]. El Profesional de la Información, 29(4). https://doi.org/ 10.3145/epi.2020.jul.26

Smyrnaios, N., Chauvet, S., \& Marty, E. (2017). L'impact de CrossCheck sur les journalistes \& les publics [The impact of CrossCheck on the journalists \& the publics]. London: First Draft. Retrieved from https://fr.firstdraftnews.org/wp-content/uploads/ sites/3/2017/12/Crosscheck_rapport_FR_1202.pdf

Stencel, M. (2015). "Fact check this": How U.S. politics adapts to media scrutiny. Reston, VA: American Press Institute. Retrieved from http://www. americanpressinstitute.org/fact-checking-project/ fact-checking-research/u-s-politics-adapts-mediascrutiny

Stencel, M., \& Luther, J. (2020, June 22). Annual census finds nearly 300 fact-checking projects around the world. Duke Reporters Lab. Retrieved from https:// reporterslab.org/annual-census-finds-nearly-300fact-checking-projects-around-the-world

Tandoc, E. C., Lim, Z. W., \& Ling, R. (2018). Defining "fake news": A typology of scholarly definitions. Digital Journalism, 6(2), 137-153.

Toporoff, S. (2016, December 8). The journey of a news product: From hackathon to the newsroom. GEN Editors Lab. Retrieved from https://medium. com/editors-lab-impact/the-case-for-hackathons3283edbd9f82

Trevisan Fossá, M. I., \& Müller, K. A. (2019). Crosscheck as a legitimization strategy of the journalism field in response to fake news. Brazilian Journalism Review, 15(3), 430-451.

Trusted News Initiative (TNI) steps up global fight against disinformation with new focus on US presidential election. (2020, July 13). BBC. Retrieved from https://www.bbc.co.uk/mediacentre/latestnews/ 2020/trusted-news-initiative

Vosoughi, S., Roy, D., \& Aral, S. (2018). The spread of true and false news online. Science, 359(6380), 1146-1151.

Wardle, C. (2017, February 16). Fake news: It's complicated. First Draft. Retrieved from https:// medium.com/1st-draft/fake-news-its-complicatedd0f773766c79

Wardle, C. (2018). The need for smarter definitions and practical, timely empirical research on information disorder. Digital Journalism, 6(8), 951-963.

Wardle, C., Pimenta, A., Conter, G., Días, N., \& Burgos, P. (2019). An evaluation of the impact of a collaboratve journalism Project on Brazilian journalists and audiences. First Draft. Retrieved from https:// firstdraftnews.org/wp-content/uploads/2019/06/ Comprova-Summary-Report-English.pdf?x91514

Westlund, O., \& Hermida, A. (in press). Data journalism and misinformation. In H. Tumber \& S. Waisbord (Eds.), Handbook on media misinformation and populism. London: Routledge.

Wiltshire, V. (2019). Keeping it local: Can collaborations help save local public interest journalism? (Reuters Institute Fellowship Paper). Oxford: Reuters Insti- 
tute for the Study of Journalism. Retrieved from https://reutersinstitute.politics.ox.ac.uk/sites/ default/files/2019-09/Vanessa_Wiltshire_JF_ paper_keeping_it_local.pdf

Wishart, E. (2018). A wire agency journalist's perspective on 'fake news.' Media Asia, 44(2), 102-106.
Young, D. G., Jamieson, K. H., Poulsen, S., \& Goldring, A. (2018). Fact-checking effectiveness as a function of format and tone: Evaluating FactCheck.org and FlackCheck.org. Journalism and Mass Communication Quarterly, 95(1), 49-75.

\section{About the Authors}

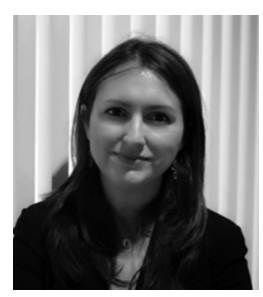

Bella Palomo is Full Professor at the University of Malaga (Spain). Palomo has focused her line of research on digital journalism during the last two decades. She has been Visiting Scholar at the Universities of Washington, Rutgers, Miami (US), and Federal de Bahia (Brazil). She is leading the project 'The Impact of Disinformation in Journalism: Contents, Professional Routines and Audiences.'

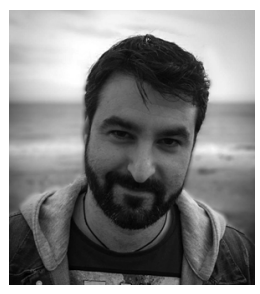

Jon Sedano is Researcher at the School of Communication of the University of Malaga (Spain). His main research interests are journalistic innovations and fact-checking. His teaching is related to photojournalism. Expert in multimedia journalism and new narratives, Sedano's professional projects have been published in Vocento newspaper group, as well as in El País. 